\title{
Button Battery In Thoracic Esophagus - A Case Report.
}

\author{
Imran Tahir', Nabil i Awan', Azam Jan', Naveed Anwar ${ }^{2}$
}

This case report may be cited as: Tahir I, Awan N, Jan A, Anwar N. Button Battery In Thoracic Esophagus - A Case Report.

J Saidu Med Coll Swat. 2021;11(2):118-120

\section{INTRODUCTION}

Button batteries are frequently used in a wide variety of electronic devices like clock, toys, torches and remote controls etc. These rounded and shiny objects are found attractive by children less than 5 years who easily ingest these disc batteries owing to their abundance ${ }^{1}$. Children presenting in pediatric emergency with ingestion of foreign body is a common and frequent encounter ${ }^{2}$. According to the American Poison Control Centre $1,810,030$ patients, annually presented in emergency with foreign body ingestion ${ }^{3,4}$. Around $80 \%$ of these are found to occur in children between 6 months and 3 years of age. In approximately $40 \%$ the event is unwitnessed making it difficult to both diagnose and subsequently identify the object that has been ingested $^{5,6}$. There have been reports of psychiatric and mentally retarded patients ingesting it voluntarily ${ }^{2}$.

The chemistry and electrical properties of these impacted cells in the esophagus has the potential to cause severe mucosal damage leading to perforation if timely intervention is not performed ${ }^{3}$. Management depends on the size, location, time since ingestion and chemical composition.

Most of the foreign bodies ingested may pass spontaneously, however about 20 percent will require removal via endoscopy with surgical intervention being needed in less than 1 percent of these patients ${ }^{7}$.

We present a case of unwitnessed button battery ingestion in a child who came to emergency after four days.

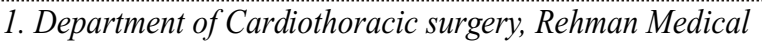 Institute Peshawar, Pakistan. \\ 2. Department of General Medicine, Rehman Medical Institute Peshawar, Pakistan}

Correspondence: Dr. Imran Tahir, Registrar, Cardiovascular \& Thoracic Surgery Rehman Medical Institute Hayatabad, Peshawar. Email: drimranswati@gmail.com,Cell: +92-346-9400494

\section{CASE HISTORY}

A 3-year-old boy was referred to us with the diagnosis of a foreign body in the esophagus. According to the parents, the child was having difficulty in swallowing for the last four days. The mother complained that for the last 04 days she had been unable to feed her son and any attempt at feeding would result in immediate vomiting after swallowing. This prompted the parents to go to the hospital where a chest radiograph showed a rounded foreign body suspected to be in the lower thoracic esophagus. A referral was made to the gastroenterology who performed an esophagogastro-duodenoscopy (OGD). The gastroenterologist visualized a round metallic object in the lower thoracic esophagus at the 25 $\mathrm{cm}$ mark. The object seemed to be ruptured with leakage of a thick black colored fluid that had pigmented the surrounding mucosa. An attempt was made for removal however bubbling of secretions was visualized by the operator who immediately abandoned the procedure citing the possibility of an esophageal perforation. He was subsequently referred to our center for surgical removal of the foreign body.

At presentation, we found the child to be dehydrated and lethargic. He was immediately admitted, and fluid resuscitation was started. A chest radiograph was repeated which showed a round opaque object in the lower part of the mediastinum with a "double-ring" or bilaminar structure. After doing baseline blood investigations a Computed Tomography of the chest was done which show a metallic foreign body in the lower part of thoracic esophagus. Due to the artefact created because of the object it was difficult to appreciate the contour of the esophagus. However, there was no major pneumomediastinum, pneumothorax or pleural effusion. Thereby, a multidisciplinary team comprising of radiologists, gastroenterologist and thoracic surgeon concluded that there was no perforation and an attempt at retrieval of the foreign body via upper Gl endoscopy was mandated at the time before embarking on a surgical approach. 
The patient was shifted to the operating room after fulfilling all pre-operative criteria. Under general anesthesia, endoscopy was done which showed the battery cell in the lower esophagus with surrounding chemical burn of mucosa with surrounding black pigmentation. After initially failing to pull the object out directly, the battery was pushed into the stomach and then removed through Roth net retrieval device. The esophagus was inspected, and no perforation was found. A nasogastric tube was passed, and patient was shifted to the Intensive Care Unit to observe for possible complication with daily chest radiograph and clinical assessment. On first postoperative day, feeding was started through the nasogastric tube and on the $5^{\text {th }}$ post-operative day the nasogastric tube was removed, and soft diet was started. The patient tolerated oral feeding well and was therefore discharged on the $6^{\text {th }}$ post-operative day.

\section{DISCUSSION}

Ingestion of foreign body most commonly occurs in children aged 3years or less ${ }^{6}$. Common objects include coins, various toys and their parts, safety pins, magnets, button batteries and food boluses ${ }^{8}$. A detailed history and clinical examination are the keystones to diagnosing esophageal foreign bodies. Dysphagia, cough, stridor, wheezing, and vomiting are the common presenting symptoms. Esophageal foreign bodies compressing the trachea can lead to stridor and expiratory wheeze. In our case the patient presented with dysphagia, vomiting and a mild cough due to a probable aspiration. Radiological imagining like conventional radiograph, computed tomography, ultrasonography and fluoroscopic upper gastrointestinal study is necessary for confirmation and localization of the foreign body ${ }^{6}$. Differentiation between coins and disk batteries are difficult on chest radiographs. For evaluation of radiolucent foreign bodies MRI can be used but it is contraindicated in case of metallic foreign bodies.

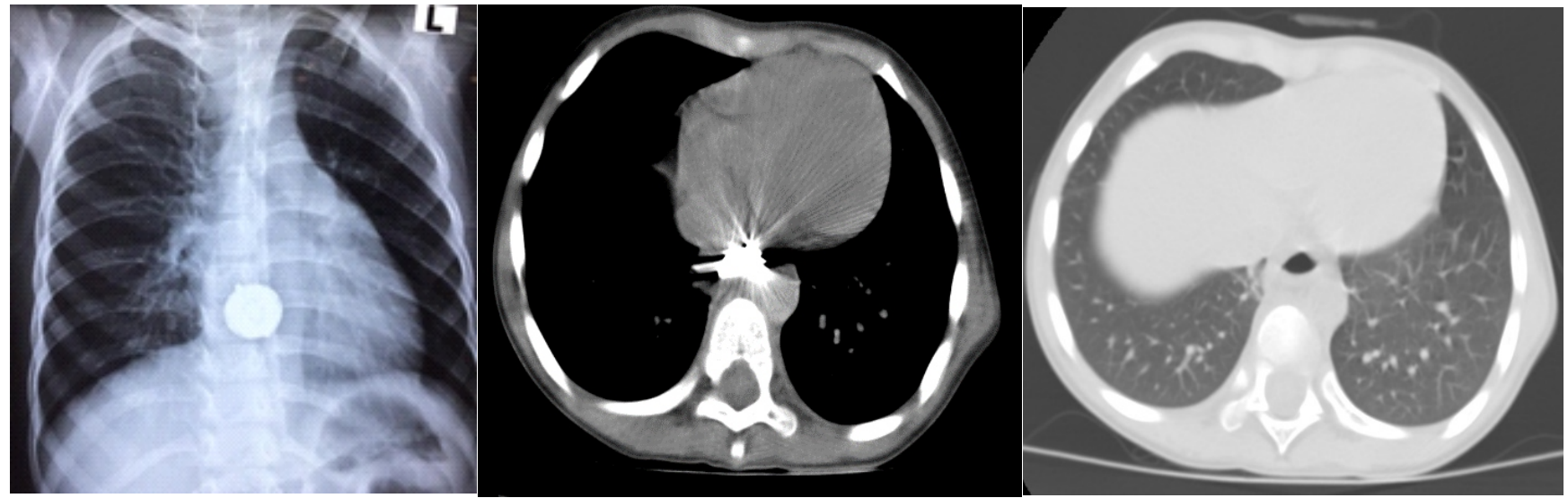

Figure 1Chest Radiograph and Computed Tomography showing foreign body in the lower part of the esophagus. No pleural effusion, pneumomediastinum or pneumothorax noted.
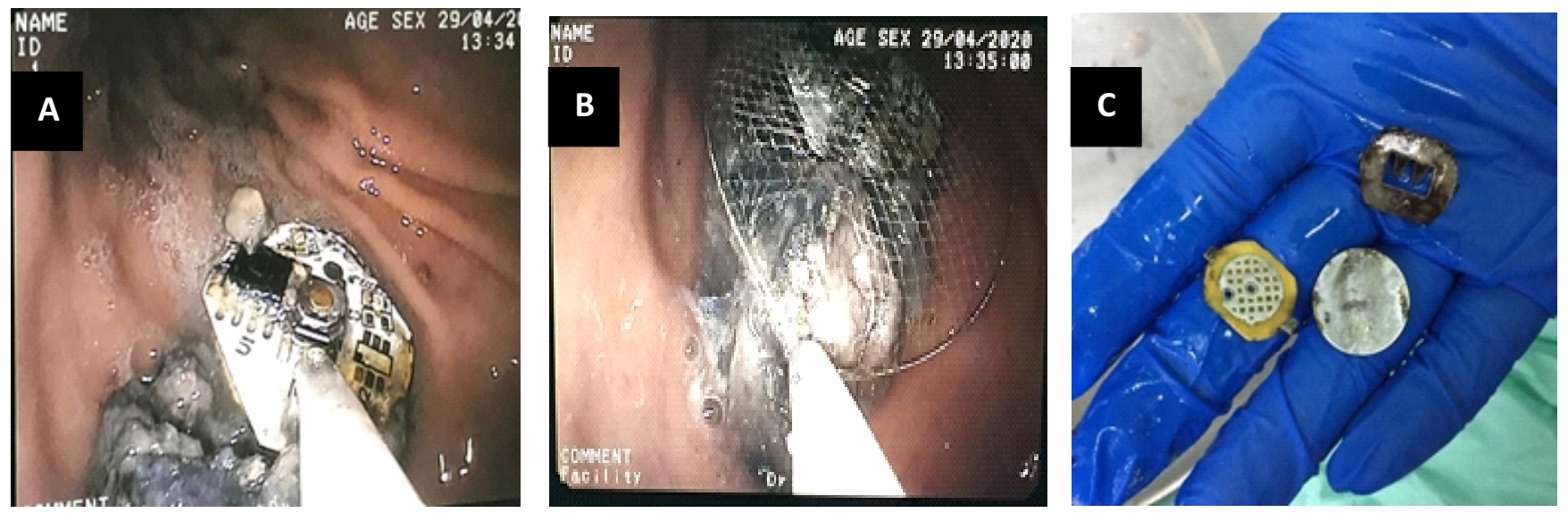

Figure 1: A) Battery cell seen in esophagus with surrounding mucosal injury. B) Retrieval of the battery with Roth net retrieval device from the stomach. C) Foreign body. 
Esophageal foreign bodies lasting for more than 24 hours should be removed to avoid serious complications like perforation and fistula formation. In a case series of 167 patients, an increased rate of complications was observed if the lodgment exceeded more than 24 hours $^{9}$. Our patient also presented after 24 hours; however, a successful retrieval was managed without any complications or the need of surgical intervention. It is pertinent to note that a battery lodged in the esophagus is an emergency, as it can potentially lead to esophageal injury to the mucosa by several different mechanisms. The electrical discharge can cause local hydrolysis leading to corrosive injury while leakage of the contents can cause liquefactive necrosis of the mucosal wall. In addition, the mere presence of the foreign body in the esophagus can potentially lead to pressure necrosis as well causing esophageal perforation within few hours ${ }^{10}$.

Various methods have been used to remove esophageal foreign bodies. They include rigid and flexible endoscopy, bougienage, Foley catheterization of the esophagus, and the penny pincher technique ${ }^{6,7}$. We removed it through flexible endoscopy, pushed it to the stomach from esophagus and then retrieved through Roth Net endoscopic device.

\section{CONCLUSION}

Batteries stuck in the esophagus can cause mucosal burns and perforation so early removal is recommended.

\section{REFERENCES}

1. Bhangu, Jashanjot Singh, Bajwa, Sukhminder Jit Singh, Anand, Smriti \& Kalsi, Kanwalpreet. 2016. Button battery ingestion: A therapeutic dilemma and clinical issues in management. Journal of the Scientific Society 43:30.

2. Mazumder, Md Wahiduzzaman, Karim, ASM Bazlul, Rukunuzzaman, Md, Begum, Fahmida \& Nahid, Khan Lamia. 2019. Foreign Body Ingestion in Children: Urgency of Management. Bangladesh Journal of Child Health 43: 106-112.

3. Banerjee R, Rao GV, Sriram PV, Pavan Reddy KS, Reddy DN. Button battery ingestion. Indian journal of pediatrics. 2005;72(2):173-78.

4. Kim SY Park B, Kong I.G, Choi HG. Analysis of ingested foreign bodies according to age, type and location: $A$ retrospective observational study. Clin. Otolaryngol. 2016, 41, 640-645.

5. Gummin DD, Mowry J.B Spyker DA Brooks, DE Fraser MO Banner W. 2016 Annual Report of the American Association of Poison Control Centers' National Poison Data System (NPDS): 34th Annual Report. Clin. Toxicol. 2017, 55, 107212-52.

6. Uyemura MC. Foreign body ingestion in children. Am. Fam. Physician 2005, 72, 2872-91
7. Wyllie R. Foreign bodies in the gastrointestinal tract. Curr Opin Pediatr 2006; 18:563-69.

8. Athanassiadi K, Gerazounis M, Metaxas E, Kalantzi N. Management of esophageal foreign bodies: a retrospective review of 400 cases. Eur J Cardiothorac Surg 2002; 21:653-58.

9. Başer M, Arslantürk H, Kisli E. Primary aortoduodenal fistula due to a swallowed sewing needle: a rare cause of gastrointestinal bleeding. Ulus TravmaAcil Cerrahi Derg 2007; 13:154-59.

10. Khalaf RT, Gurevich Y, Marwan Al, et al. Button Battery Powered Fidget Spinners: A Potentially Deadly New Ingestion Hazard for Children. J Pediatr Gastroenterol Nutr 2018; 66:595-9

DATA SHARING STATEMENT: The data that support the findings of this study are available on request from the corresponding author. The data are not publicly available due to privacy or ethical restrictions.

CONFLICT OF INTEREST: Authors declared no conflict of interest.

GRANTED SUPPORT AND FINANCIAL DISCLOSURE: Nil

\section{AUTHOR'S CONTRIBUTION}

Following authors have made substantial contributions to the manuscript as under

Tahir I: Concept and design of study, Collection of data, statistical analysis

Anwar N: Writing of manuscript, critical review of manuscript

Awan N: Analysis and interpretation of data, $\begin{array}{ll} & \text { statistical analysis } \\ \text { Jan } & \text { Data collection, bibliography }\end{array}$

Authors agree to be accountable for all aspects of the work in ensuring that questions related to the accuracy or integrity of any part of the work are appropriately investigated and resolved. 